to random variation, which seems unlikely, or to the effect of variables not studied in this survey. Further studies, using other variables, such as serum-lipid levels, smoking habit, amount of physical activity, and, when such tests become available, assessment of thrombotic activity, would clearly be of interest.

\section{Summary}

The area of aortic surface occupied by different types of plaque was determined by a tracing and planimetry technique on 336 unselected necropsy specimens, and on 116 specimens from patients with cardiac infarction.

The area of the standard aortic segment studied was found to increase with age in a linear fashion, and the implications of this for the assessment and interpretation of aortic disease are discussed.

The area of fatty streaking was found to be unrelated to age, sex, aortic area, and diastolic blood-pressure, whereas the area occupied by raised plaques was related to these factors. These findings emphasize the differential behaviour of the two types of plaque. Although raised plaques showed a relationship to these factors, some $60-80 \%$ of the variability of aortic disease observed in our sample was not accounted for by the factors considered, nor was any explanation found for the increased amount of disease seen in patients with myocardial infarction. Random variations, or the effect of factors other than those studied, must account for this residual variability and for the differences between a group of patients with cardiac infarction and an unselected necropsy group.

We are grateful to Sir George Pickering for advice and encouragement, and to Dr. N. T. J. Bailey and Mr. J. F. Scott, of the Unit of Biometry, Oxford University, for their interest in the statistical problems. The work was done while J. R. A. M. was a Clinical Research Fellow of the Medical Research Council, while C.J.S. was a C. J. Martin Research Fellow of the National Health and Medical Research Council of Australia, and while A. Z. was the holder of a N.A.T.O. Science Fellowship of the National Research Council of Canada.

\section{REFERENCES}

Cranston, W. I., Mitchell, J. R. A., Russell, R. W. R., and Schwartz, C. J. (1963). F. Atheroscler. Res. In press.

Davis, D., and Klainer, M. J. (1940). Amer. Heart F., 19, 185.

Dotter, C. T., and Steinberg, I. (1949). Radiology, 52, 353.

Finlayson, R., Symons, C., and Fiennes, R. N. T.-W. (1962). Brit. med. 7., $1,501$.

Hill, K. R., Camps, F. E., Rigg, K., and McKinney, B. E. G. (1961). Ibid., 1, 1190.

Holman, R. L., McGill, H. C., Strong, J. P., and Geer, J. C. (1958). Amer. 7. Path., 34, 209.

Mitchell, J. R. A., and Schwartz, C. J. (1962). Brit. med. F., 1, 1293.

(1963). Brit. Heart 7., 25, 1.

Oliver, M. F., and Boyd, G. S. (1959). Lancet, 2, 690

Paterson, J. C., Mills, J., and Lockwood, C. H. (1960). Canad. med. Ass. f., 82, 65.

Rivin, A. U., and Dimitroff, S. P. (1954). Circulation, 9, 533.

Sacks, M. I. (1960). Ibid., 22, 96.

Schwartz, C. J., and Mitchell, J. R. A. (1962a). Postgrad. med. f., 38, 25.

- (1962b). Circulat. Res., 11, 63.

- (1962c). Brit. Heart F., 24, 761.

Spitzer, R. S., Lee, K. T., and. Thomas, W. A. (1957). Amer. Heart F., 53, 805.

Strong, J. P., Wainwright, J., and McGill, H. C. (1959). Circulation, 20, 1118.

Turnbull, H. M. (1915). Quart. F. Med., 8, 201.

Wilens, S. L. (1947). Amer. F. Path., 23, 793.

Wilkins, R. H., Roberts, J. C., and Moses, C. (1959). Circulation, 20, 527.

\title{
Antigenic Properties of Human Tumours : Delayed Cutaneous Hypersensitivity Reactions
}

\author{
L. E. HUGHES,* M.B., F.R.c.s., F.R.A.C.s. ; B. LYTTON, † M.B., F.R.C.s.
}

Brit. med. F., 1964, 1, 209-212

The possibility of controlling human cancer by immunological means continues to excite the interest of many workers. The successful therapeutic application of such methods must depend primarily on the presence of specific cancer antigens, and it must be admitted that such antigens have not yet been demonstrated to the satisfaction of many immunologists. Efforts have been made to demonstrate tumour antigenicity in relation to the host by a variety of methods. In 1930 Witebsky produced an antiserum to human stomach cancer in guineapigs. He then absorbed these antisera with alcoholic extracts of normal stomach and found that the antiserum was still capable of producing a precipitation reaction against the cancer extract. This suggests that there is a different antigen present in gastric cancer which is not present in the corresponding normal tissue. Zilber et al. (1959) claim to have demonstrated specific tumour antigens by immunizing guinea-pigs with tumour extract. The animals were subsequently desensitized to normal tissue extracts, and, following this, were still found to develop anaphylaxis when challenged with tumour extracts. Graham and Graham (1955) found positive complement-fixation reactions in the sera of 12 out of 48 patients tested against extracts of their own tumours. Finney, Byers, and Wilson (1960) were able to demonstrate precipitating antibody in the serum of patients against a saline extract of their own tumour. Furthermore, they were able to demonstrate a rise in antibody titre after intramuscular injection of tumour extract and adjuvant, and in some cases after radiotherapy. Most recently, Nairn, Philip, Ghose, Porteous, and Fothergill (1963) have shown by means of gel-diffusion reactions the presence of apparently specific serum antibody to kidney carcinoma in a patient who was immunized by homologous human renal carcinoma.

In addition to this in vitro evidence of tumour antigenicity, there is much to suggest the presence of an immune response to the tumour on the part of the host, but this evidence is largely of an indirect nature. Black and Speer (1959) have shown that there is a correlation between the degree of

* Department of Surgery, King's College Hospital Medical School London. (Present address: Department of Surgery, University of Queensland, Brisbane, Australia.)

† Department of Surgery, King's College Hospital Medical School London. (Present address: Deparment of Urology, Yale University School of Medicine, New Haven, Connecticut, U.S.A.) 
lymphocytic infiltration of a tumour and the length of survival of the patient when the tumour has been removed. They suggest that the lymphocytic infiltration represents an immunological response to the tumour cells. Southam and Moore (1958) inoculated HeLa-cell suspensions into patients with advanced cancer and found that in some instances the inoculated cells grew and even resulted in metastases to the regional lymph nodes. Similar inoculations into healthy human volunteers were rejected in the same way as any homograft. This suggests a depression of immunological reactivity in patients with advanced malignancy. The most direct evidence of a host-antibody response is that of Grace and Kondo (1958), who demonstrated the presence of humoral antibody in certain patients with rapidly growing breast cancers, by direct and passive transfer skin reactions, to autogenous aqueous tumour extracts.

The primary problem of cancer immunology remains the satisfactory demonstration of specific cancer antigens, should they exist. Most previous workers have been concerned with the demonstration of circulating antibodies. However, the histological picture described by Black and Speer (1958), and shown by them to be associated with increased survival of a patient with cancer, resembles a delayed or cellular type of immune reaction, which also has marked similarities to homograft rejection.

This study was undertaken to determine whether a malignant tumour arising spontaneously in an individual exhibited sufficient antigenic differences from the host to be regarded as a type of homograft. Brent, Brown, and Medawar (1958) have shown that the immune response to a homograft may be manifested by a delayed cutaneous hypersensitivity reaction of the tuberculin type in the recipient to a cell-free extract from the donor. We have employed this principle in an attempt to determine whether patients with cancer exhibit a delayed cutaneous hypersensitivity to similar cell-free extracts of their own tumours.

\section{Methods}

Patients undergoing surgery for a variety of malignant tumours were studied. Pieces of tissue weighing from 6 to $8 \mathrm{~g}$. were removed from the deeper parts of fresh tumours which had been excised at operation. Pieces of corresponding normal tissue-for example, gastric mucosa for gastric carcinoma-from the same patient were obtained, taking care that the normal tissue was well away from the malignant area. Both normal and tumour specimens were immediately processed under sterile conditions in the following manner, to obtain an antigenically potent cell-free extract of the tissue. The tissues were cut into fine sections on a cryostat, suspended in distilled water, and homogenized in a Waring blender. The homogenates were then subjected to ultrasonic disintegration for 15 seconds to complete the dissolution of the cell membranes. The solutions were restored to isotonicity with hypertonic saline and centrifuged at $2,500 \mathrm{~g}$ for 10 minutes to remove the cell membranes and tissue debris. The supernatant was decanted and centrifuged at 26,000 $g$ for 60 minutes to obtain the smaller cytoplasmic particles. The deposit thus obtained was then resuspended in 1-2 ml. of normal saline and the resultant solution was used as the antigen for intradermal injection. A portion of each solution was lyophilized, and it was found that the concentration of the solution varied from 15 to $30 \mathrm{mg}$. of solid material per $\mathrm{ml}$. Each solution was cultured aerobically and anaerobically for 48 hours prior to injection to demonstrate freedom from bacterial contamination. Those showing the presence of bacteria were rejected. Tumours and control tissues from the gastro-intestinal tract were washed thoroughly with sterile saline and treated with neomycin.
A $0.1 \mathrm{ml}$. of suspension of tumour extract and the same volume of suspension of normal tissue extract was injected intradermally at separate sites into the patient from whose tissues the extracts had been prepared. The injection sites were inspected at 10 minutes, one hour, six hours, and then twice daily for the next three days. The reactions were recorded as positive if a palpable weal with an area of erythema of more than $8 \mathrm{~mm}$. diameter was present after 24 hours. A reaction smaller than this but still a definite one was recorded as a weak positive. Three patients underwent biopsy of the skin at the height of a positive reaction, and the histological appearances were similar to those seen in hypersensitivity reactions-namely, oedema, necrosis, and infiltration with polymorphonuclear cells in the early reaction, and infiltration with mononuclear cells, particularly around blood-vessels and sweat glands, in the later reactions. However, in each case the histological picture was to some extent a mixed one in which. either immediate or delayed elements predominated.

\section{Results}

Fifty patients have had the delayed hypersensitivity response to their own malignant tumour investigated. In all but 15 cases an extract of normal tissue from the same individual was prepared in the same way as the cancer extract to act as a control. In the remaining 15 cases no control was used-either because the tissue was not available or because the preparation was not sterile.

The results are shown in Table I. A definite positive response with a negative control was obtained in $9(27 \%)$ out

TABLE I.-Delayed Cutaneous Hypersensitivity Reactions to Tumour Extracts

\begin{tabular}{|c|c|c|c|c|c|c|c|}
\hline \multirow{2}{*}{\multicolumn{3}{|c|}{ Site of Tumour }} & \multirow{2}{*}{ Total } & \multicolumn{2}{|c|}{ With Control } & \multicolumn{2}{|c|}{ Without Control } \\
\hline & & & & Positive & Negative & Positive & Negative \\
\hline $\begin{array}{l}\text { Breast } \\
\text { Colon } \\
\text { Lung } \\
\text { Stomach } \\
\text { Others }\end{array}$ & $\begin{array}{l}\cdots \\
\cdots \\
\cdots \\
\cdots\end{array}$ & $\begin{array}{l}\cdots \\
\cdots \\
\cdots \\
\cdots\end{array}$ & $\begin{array}{c}22^{*} \\
14 \\
4 \\
6^{*} \\
4^{*}\end{array}$ & $\begin{array}{l}3 \\
3 \\
2 \\
1 \\
-\end{array}$ & $\begin{array}{r}11 \\
6 \\
2 \\
3 \\
-\end{array}$ & $\begin{array}{l}2 \\
\overline{-} \\
\overline{1}\end{array}$ & $\begin{array}{l}4 \\
5 \\
1 \\
2\end{array}$ \\
\hline All cases & . & . & $50^{*}$ & 9 & 22 & 3 & 12 \\
\hline
\end{tabular}

* Discrepancy in total figures is due to exclusion of four cases; two cases of carcinoma of breast were classified as weak positive reactions, and two other casesone oesophagus
control extracts.

of 33 patients. In a further two cases a weak positive reaction was obtained. In two patients a positive response was invalidated by a positive reaction at the site of the control injection. Three of the patients without control extracts had positive reactions, while the other 12 uncontrolled patients showed no reaction to their cancer extract, a positive rate of $20 \%$. Extracts were also made from three benign conditions -a chronic duodenal ulcer, a chronically infected lymph node, and a simple fibroadenoma of the breast. In each case the response to the tissue extract was negative. Four of the patients who showed positive delayed reactions to their tumour extracts also showed a definite immediate component -the reaction appearing within 20 minutes, reaching a maximum in 8 to 12 hours, and then diminishing slightly before being superseded by a delayed response. The immediate reactions occurred with tumours from four different sites-breast, ovary, caecum, and stomach. No immediate reactions were obtained with the control solutions.

\section{Discussion}

The results indicate that about one-quarter of patients with a variety of malignant tumours exhibit a delayed cutaneous hypersensitivity reaction to cell-free extracts of their own 
tumour, and that a smaller proportion also show an immediate type of reaction. In our patients there appears to be no correlation between the histology of the patient's disease and the presence of a positive skin reaction. This can be seen from Table II, where the incidence of positive and negative reactions

TABLE II.--Skin Reactions Correlated with Pathology of the Tumours

\begin{tabular}{|c|c|c|c|c|c|}
\hline Histology & & $\begin{array}{c}\text { Lymph } \\
\text { Nodes } \\
\text { not Involved }\end{array}$ & $\begin{array}{l}\text { Lymph } \\
\text { Nodes } \\
\text { Involved }\end{array}$ & $\begin{array}{l}\text { No Lymph } \\
\text { Nodes } \\
\text { Found }\end{array}$ & Total \\
\hline Well differentiated & \{ & $\begin{array}{l}3 \text { positive } \\
6 \text { negative }\end{array}$ & $\begin{array}{l}2 \text { positive } \\
5 \text { negative }\end{array}$ & $\begin{array}{l}2 \text { positive } \\
0 \text { negative }\end{array}$ & $\begin{array}{l}7 \text { positive } \\
11 \text { negative }\end{array}$ \\
\hline Poorly differentiated & \{ & $\begin{array}{l}3 \text { positive } \\
7 \text { negative }\end{array}$ & $\begin{array}{l}3 \text { positive } \\
11 \text { negative }\end{array}$ & $\begin{array}{l}1 \text { positive } \\
1 \text { negative }\end{array}$ & $\begin{array}{l}7 \text { positive } \\
19 \text { negative }\end{array}$ \\
\hline Total & $\ldots$ & $\begin{array}{l}6 \text { positive } \\
13 \text { negative }\end{array}$ & $\begin{array}{r}5 \text { positive } \\
16 \text { negative }\end{array}$ & & \\
\hline
\end{tabular}

is set out in relation to the histology of the tumour. Tumours have been divided into those which are well differentiated and poorly differentiated (although it is realized that this is largely a subjective assessment), and again into those where the lymph nodes were found to be involved by or free from metastases. It can be seen that the positive reactions are fairly evenly distributed among the various groups. It is too early as yet to determine whether there is a correlation between immune response and long-term survival in these cases.

In spite of the possible non-specific mechanisms which might produce a similar cutaneous response, we believe that these are truly immunological in nature. A non-specific reaction may occur as a result of the intradermal injection of any solution. This varies greatly in degree from patient to patient, but in the same patient is always equal for similar volumes of injectant, irrespective of the nature of the solution used. These responses always disappear within four to five hours, and this allows ready differentiation from the more delayed specific reactions. A further source of confusion might arise from pharmacological reactions. We have often seen these when using the supernatant instead of the deposit as a test solution, particularly when the tissues are derived from the stomach or lung. These reactions are very characteristic, appearing as a turgid, welldemarcated weal, following approximately the same time sequence as an immediate type reaction, but being much more intense and with a much more clearly defined perimeter. We have not been troubled by these reactions using the cytoplasmic deposit, as the supernatant fluid is carefully removed before resuspending the solid matter in saline.

We have estimated the dry weight of the solid matter in the tumour and control suspensions, to exclude the possibility that the greater reaction to cancer extracts might be due to a greater amount of solid material present. Comparison of the dry weight has shown that this is not so. In fact, there is usually a larger amount of material extracted from the normal tissues than from the corresponding cancer.

Finally, it remains a possibility that the reactions are due to infection. The presence of living bacteria has been excluded by culture of the extracts prior to injection, but bacterial debris could result in a delayed hypersensitivity reaction. We feel that this is unlikely, for the following reasons: (1) The incidence of positive reactions was the same when the tumour was a peripheral breast carcinoma, where infection would not be present, as when the tumour was from the gastro-intestinal tract. (2) Specimens taken from the deeper parts of a tumour, even of the colon, are often sterile, so that there must be greater contamination with bacterial debris in the crypts of the mucosa, used as a normal control, than with the tumour itself. None of the patients have shown hypersensitivity to the bacterial debris that must be present in colonic mucosa.

It is difficult to explain the two cases that showed positive reactions to both cancer and control extracts. It is probable that these represent a non-specific reaction, but just possible that the tissues used as a control have undergone pre-malignant change resulting in antigenic differences.

Brent et al. (1958) have demonstrated quite clearly that the reaction against the skin homograft in guinea-pigs can be made to express itself as a hypersensitivity reaction of the delayed type by both the direct and the transfer reactions. Lawrence (1957) has pointed out how close the analogy is between the homograftrejection reaction and the delayed cutaneous hypersensitivity reaction of the tuberculin type, the principal points of similarity being the mode of induction of sensitivity, the latent period, specificity of the antigenic source, and the ability to transfer the sensitivity with cells but not with serum. It is highly suggestive, therefore, that the cutaneous responses which we have elicited represent a reaction on the part of the individual to his tumour as if it were in fact a homograft.

We are still faced with the problem, however, of tumour survival and progression despite a positive response. The delayed hypersensitivity response may in some instances not contribute to the host-defence mechanism. It could possibly be a response to secondary antigens produced by the tumour either as a result of cellular activity or death of the cells with liberation of foreign antigens. A parallel situation may occur in patients with tuberculosis where, despite the presence of a delayed hypersensitivity response, the disease progresses steadily to a fatal conclusion. Lawrence (1957) has suggested that once the tumour has become well established it overrides a degree of immunological reactivity capable of destroying the normal homograft. That there is a depression of the immunological responsiveness in advanced malignant disease has been shown by the experiments of Grace and Kondo (1958), and Lytton, Hughes, and Fulthorpe (1964). They have demonstrated a decrease of the homograft response in advanced disease and a poor humoral antibody response in patients with advanced malignant disease.

It would seem more reasonable, therefore, to attempt to stimulate the antibody response in patients with early malignant lesions before their immunological responses become depressed, particularly if they exhibit evidence of delayed cutaneous hypersensitivity to extracts of their own tumours. Perhaps related to this is the suggestion of Crile (1959) that it is wrong to remove the unaffected regional lymph nodes in early carcinoma of the breast as this may interfere with the host-defence mechanism, for the removal of the regional lymph nodes has been shown to delay the rejection of a skin homograft.

The demonstration of delayed cutaneous hypersensitivity in a significant number of patients to their own tumours provides further evidence of the existence of specific antigenic differences between normal and tumour cells. This may represent a possible starting point for an immunological attack on the disease and encourage the further development of existing methods in current use for increasing the patient's immune response to his tumour. There is still, however, no adequate explanation of the nature of the basic biological change in the host-tumour relationship when a malignant tumour undergoes progressive growth despite the presence of what appears, from this study, to be some degree of immunological responsiveness on the part of the host to his tumour.

\section{Summary and Conclusions}

Fifty patients suffering from malignant disease have been injected with cell-free extracts of their own tumours and with normal tissue extracts as controls, to investigate possible immunological reactions.

Delayed cutaneous hypersensitivity reactions have been demonstrated in one-quarter of the patients and a small number have also shown an immediate type response.

Positive results have been obtained with tumours from a variety of organs, and there does not appear to be any correla- 
tion between the presence of a cutaneous response and the histology of the tumour.

It is suggested that the reactions obtained are true immunological reactions, and that they are due to the presence of specific cancer antigens in the tumours concerned.

We would like to thank Mr. Harold Edwards and Mr. J. G. Murray for their help and advice in the carrying out of this work and in the preparation of this paper. We are also grateful to the members of the surgical staff of King's College Hospital for their co-operation in this study. The work was carried out during the tenure of whole-time grants from the British Empire Cancer Campaign.
REFERENCES

Black, M. M.. and Speer, F. D. (1959). Int. Abstr. Surg., 109, 105.

Brent, L., Brown, J., and Medawar, P. B. (1958). Lancet, 2, 561.

Crile, G.'(1959). Postgrad. Med., 26, 64.

Finney, J. W., Byers, E. H., and Wilson, R. H. (1960). Cancer Res., 20, 351 .

Grace, J. T., and Kondo, T. (1958). Ann. Surg., 148, 633.

Graham, J. B., and Graham, R. M. (1955). Cancer, 8, 409.

Lawrence. H.'S. (1957). Ann. N.Y. Acad. Sci., 64, 826.

Lytton, B., Hughes, L. E., and Fulthorpe, A. J. (1964). In press.

Nairn, R. C., Philip, J., Ghose, T., Porteous, I. B., and Fothergill, J. E. (1963). Brit. med. F., 1, 1702.

Southani, C. M., and Moore, A. E. (1958). Ann. N.Y. Acad. Sci., 73, 635.

Witebsky, E. (1930). Klin. Wschr., 9, 58.

Zilber, L. A. (1958). Advanc. Cancer Res., 5, 291.

\title{
Folic-acid Deficiency in Rheumatoid Arthritis
}

\author{
K. R. GOUGH,* M.D., M.R.C.P. ; C. MCCARTHY,* M.D., M.R.C.P. ; A. E. READ,* M.D., M.R.C.P. \\ D. L. MOLLIN, $\dagger$ M.B., B.SC. ; A. H. WATERS, $\uparrow \S$ M.B., B.S.
}

Brit. med. F., 1964, 1, 212-217

Megaloblastic anaemia (other than pernicious anaemia) associated with rheumatoid arthritis has been reported in two patients by Doig et al. (1957) and in a further six patients by Partriuge and Duthie (1963). The cause of the megaloblastic anaemia in these patients was uncertain, but it was suggested that it might be due to failure to utilize vitamin $B_{12}$ absorbed from the diet (Partridge and Duthie, 1963).

During the past two years we have studied tour patients with rheumatoid arthritis who suffered from megaloblastic anaemia other than pernicious anaemia. In each instance the cause of megaloblastic anaemia was folic-acid deficiency. The purpose of this paper is to report the findings in these patients and the results of a subsequent survey of the incidence of folic-acid deficiency in a randomly selected group of patients with rheumatoid arthritis. In the course of this survey two further patients with megaloblastic anaemia were discovered and details of these are also given. A summary of these observations was reported at a Scientific Meeting of the Royal College of Physicians of London on 30 November 1962 (Gough et al., 1962) and in a letter (Mollin et al., 1963).

\section{Patients Studied}

Patients with Megaloblastic Anaemia.-Six patients with megaloblastic anaemia were studied: four of these were admitted to the Hammersmith Hospital and two were found among the survey group of 46 patients with rheumatoid arthritis who were selected at random from the diagnostic index of the Records Department at the Bristol Royal Infirmary. These two patients were admitted to the Department of Medicine, Bristol Royal Infirmary, for further investigation.

The Survey.-Forty-six patients were studied in the survey. They attended the Department of Medicine at the Bristol Royal Infirmary for a day. An assessment was made of the duration of the disease, and the functional disability of the patients was graded as "mild," "moderate," or " severe." Details of the drugs used in treatment were noted, and if a patient was found

\footnotetext{
- From the University Department of Medicine, at the Bristol Royal Infirmary.

† From the Department of Haematology, Postgraduate Medical School of London.

$\mp$ In recespt of a grant from Medical Research Council.

$\checkmark$ University of Queensland Travelling Scholar in Medicine.
}

to be taking barbiturates or anticonvulsant drugs he was excluded from the survey. A careful dietary history was taken and the haemoglobin, haematocrit, white-cell count, and E.S.R. were measured and a blood film was examined. Serum was taken for serum folate and vitamin $\mathrm{B}_{12}$ assays, and the urinary excretion of formimino-glutamic acid was estimated. Similar studies were made on 57 control subjects who were all healthy non-medical employees of the United Bristol Hospitals.

\section{Methods}

1. Haematological methods were those described by Dacie (1956)

2. Urinary Formimino-glutamic Acid.-Patients were given an oral loading dose of $15 \mathrm{~g}$. of histidine and urinary Figlu was detected by conventional voltage electrophoresis on cellulose acetate strips (Kohn et al., 1961). The method is not strictly quantitative, but a rough grading of the Figlu "spot" was made as,+++ , or +++ , where the +++ spot was equivalent to a urinary Figlu concentration of more than 500 $\mu \mathrm{g} . / \mathrm{ml}$.

3. Serum-folate levels were measured by microbiological assay with Lactobacillus casei ATCC 7469 (Waters and Mollin, 1961) (normal range 5.9-21 m $\mu$ g./ml.). Patients with megaloblastic anaemia due to folic-acid deficiency have serum-folate levels less than $4 \mathrm{~m} \mu \mathrm{g}$. $/ \mathrm{ml}$. (Waters and Mollin, 1961).

4. Serum-vitamin- $B_{12}$ levels were measured by microbiological assay using Lactobacillus leichmanii (Spray, 1955) (normal range $140-900 \mu \mu \mathrm{g} . / \mathrm{ml}$.). Patients with pernicious anaemia have serum-vitamin- $B_{12}$ concentrations of less than $100 \mu \mu \mathrm{g} /$ ml. (Mollin, 1960 ; Matthews, 1962).

5. Dietary History.-Detailed dietary histories were obtained by the hospital dietitian. An assessment was made of the average daily intake of folic acid, vitamin $\mathrm{B}_{12}$, ascorbic acid, iron, protein, and total calories, using the values quoted by McCance and Widdowson (1960). The figures quoted are for the uncooked dietary content:

(It must be stressed that the calculated "folic-acid" content of the diet is an arbitrary figure, and serves only as an index for comparison of the dietary "folic-acid" intake of different groups of patients. The figures obtained by this method do 